\title{
Retratos contemporâneos da Educação do Campo: movimentos investigativos no Vale do Jiquiriçá-BA
}

Mônica de Almeida Santos ${ }^{1}$, Alcione de Almeida Santos ${ }^{2}$, Maria Célia Santana Orrico ${ }^{3}$, Mariana Martins de Meireles ${ }^{4}$

${ }^{1}$ Universidade Federal do Recôncavo da Bahia - UFRB. Centro de Formação de Professores - CFP. Avenida Nestor de Melo Pita, 535, Centro, Amargosa - BA. Brasil. monicaalmeida13@gmail.com. ${ }^{2}$ Universidade Federal do Recôncavo da Bahia - UFRB. ${ }^{3}$ Universidade Federal do Recôncavo da Bahia - UFRB. ${ }^{4}$ Universidade Federal do Recôncavo da Bahia - UFRB.

RESUMO. Esse artigo é resultado de uma pesquisa realizada no povoado do Serrote, zona rural do município de Elísio MedradoBahia, no âmbito dos estudos efetivados pelo Observatório em Educação do Vale do Jiquiriçá (OBSERVALE/UFRB), que tem como finalidade ampliar estudos e promover debates sobre a Educação do Campo no Território do Vale do Jiquiriçá. As análises que resultam nesse texto decorrem da pesquisa: "Retratos da Educação do Campo: Cenários Contemporâneos", realizada com 12 escolas do campo e 12 professores e representantes do poder público. A investigação ancorou-se metodologicamente em uma pesquisa de abordagem qualitativa, através do uso de entrevistas semiestruturadas e da observação do contexto escolar. Neste artigo, especificamente, utilizamos os dados de uma das escolas investigadas, tendo em vista uma análise mais apurada de relatos de duas colaboradoras e de dados recolhidos na pesquisa de campo. O estudo revelou a presença de um modelo urbanocêntrico de educação que se distancia dos princípios e concepções que pautam o movimento por uma Educação do Campo no Brasil, revelando a predominância de uma educação orientada por um currículo homogêneo e descolado dos contextos dos estudantes, desvelando assim, retratos de uma Educação Rural, ainda que estejamos em tempos de luta por uma Educação do Campo.

Palavras-chave: Educação do Campo, Classes Multisseriadas, Formação de Professores.

\begin{tabular}{|l|l|l|l|l|l|l|l|}
\hline Rev. Bras. Educ. Camp. & Tocantinópolis & v. 3 & n. 1 & p. 204-222 & jan./abr. & 2018 & ISSN: 2525-4863 \\
\hline
\end{tabular}




\title{
Contemporary Peasant Education Pictures: Investigative Movements in the Jiquiriçá Valley-BA
}

\begin{abstract}
This article is the result of a survey carried out in the village of Serrote, a rural area in the municipality of Elísio Medrado-Bahia, in the framework of studies carried out by the Jiquiriçá Valley Observatory in Education (OBSERVALE/UFRB), whose purpose is to expand studies and promote debates on Peasant Education in the Jiquiriçá Valley Territory. The analyzes that result in this text derive from the research: "Peasant Education Pictures: Contemporary Scenarios", carried out with 12 rural schools and 12 teachers and representatives of the public power. The research was anchored methodologically in a qualitative approach research, through the use of semi-structured interviews and the observation of the school context. In this article, specifically, we used data from one of the schools investigated, aiming at a more accurate analysis of reports from two collaborators and data collected in the research. The study revealed the presence of an urbancentric model of education that distances itself from the principles and conceptions that guide the movement for a Peasant Education in Brazil, revealing the predominance of an education oriented by a homogeneous curriculum and detached from the contexts of the students, revealing thus, portraits of a Rural Education, although, we are in times of struggle for a Peasant Education.
\end{abstract}

Keywords: Peasant Education, Multi-series Class, Teacher Education. 


\section{Contemporáneo retratos de Educación Rural: Movimientos de Investigación en Valle Jiquiriçá-BA}

RESUMEN. Este artículo es el resultado de una investigación realizada en la ciudad de Serrote, municipio rural de Elísio Medrado-Bahía, en los estudios efectuados por el Centro de Educación Jiquiriçá Valley (OBSERVALE / UFRB), que tiene como objetivo ampliar los estudios y promover debates en Educación en el Campo en el Territorio Jiquiriçá Valle. Las análisis que dan lugar a este texto son el resultado de la investigación: "Retratos Educación en el Campo: Escenarios Contemporáneos", realizado con 12 escuelas en el campo y 12 profesores y representantes del gobierno. La investigación metodológicamente apoyada en una investigación cualitativa, a través del uso de entrevistas y observación del contexto escolar. En este artículo, en concreto, se utilizan los datos de una de las escuelas, con el fin un análisis más detallado de dos colaboradores y los informes de los datos recogidos en la investigación de campo. El estudio reveló la presencia de un modelo de educación urbano céntrico que distancia de los principios y conceptos que guían el movimiento de Educación en el Campo en Brasil, que revela el predominio de una educación guiada por un plan de estudios y los hipsters homogénea de los contextos de los estudiantes, presentación por lo tanto retratos de una Educación Rural, sin embargo, estamos en tiempos de lucha por una Educación en el Campo.

Palabras clave: Educación en el Campo, Clase Multiseraria, Formación de Profesores. 
Introdução: os nascedouros desses escritos...

O presente artigo é resultado de uma pesquisa de campo realizada no povoado do Serrote, zona rural do município de Elísio Medrado-Bahia, no âmbito dos estudos efetivados pelo Observatório em Educação do Vale do Jiquiriçá (OBSERVALE), vinculado à Universidade Federal do Recôncavo da Bahia (UFRB), que tem como finalidade ampliar estudos e promover debates sobre a Educação do Campo no Território do Vale do Jiquiriçái

As análises apresentadas decorrem da pesquisa: "Retratos da Educação do Campo: Cenários Contemporâneos", que buscou analisar cenários contemporâneos da Educação do Campo no Território Vale do Jiquiriçá-BA e, mais especificamente, nos municípios de Amargosa, Mutuípe e Elísio Medrado. A referida pesquisa foi realizada com 12 escolas do campo e 12 professores e representantes do poder público dos respectivos municípios.

A investigação ancorou-se metodologicamente em uma pesquisa de abordagem qualitativa, através do uso de entrevistas semiestruturadas e da observação do contexto escolar. Os dados recolhidos através de pesquisa de campo constituem-se como um importante acervo de narrativas orais dos colaboradores e dos contextos investigados.
Nesse viés, vale destacar que o estudo aborda especificamente os resultados da pesquisa que foi desenvolvida na Secretaria de Educação de Elísio Medrado e em uma escola do campo do Serrote, de modo que estiveram envolvidas na investigação a coordenadora das escolas do campo e uma das professoras que atuam nesse contexto.

A Educação ofertada em contextos campesinos, historicamente, sempre foi negligenciada e tratada com inferioridade e descaso pelos governantes, pela elite brasileira e pelas políticas públicas, enquanto que o espaço urbano sempre foi apresentado como padrão de superioridade e modernidade que deveria ser seguido e adotado, inclusive, no que diz respeito às propostas educacionais.

Nesse sentido, nota-se que no cenário brasileiro, "a educação do campo tem se caracterizado como um espaço de precariedade por descasos, especialmente pela ausência de políticas públicas para as populações que lá residem" (Pinheiro, 2011, p. 1). Todavia, apesar da trajetória de negação e ausência, nos últimos anos surgiram movimentos sociais que impulsionaram a construção de um projeto de desenvolvimento social e educacional, convocando a participação dos povos do campo, valorizando, desse modo, suas 
mais diversas formas de vida e seus anseios.

Nessa perspectiva, dentre os objetivos desses movimentos, destaca-se a busca por uma educação de qualidade, de modo que as próprias origens da Educação do Campo são marcadas por uma série de lutas e desafios protagonizados pelos movimentos sociais, que iniciam com a luta pela terra e posteriormente com a luta por uma educação de qualidade, desta vez, com face campesina.

Sabemos que embora inúmeros avanços já tenham sido alcançados, ainda há muitas dificuldades e desafios que merecem destaques e visibilidades no contexto da luta por uma Educação do Campo. Tomando esse cenário emblemático de avanços e retrocessos, nosso trabalho de pesquisa orientou-se a partir do seguinte problema: "Que retratos constituem a Educação do Campo no Território do Vale do Jiquiriçá- BA, considerando a conjuntura desse território de identidade?".

Para tanto, buscamos descrever aspectos do cotidiano escolar vivenciados por estudantes e professores de escolas do campo; identificar elementos das práticas pedagógicas desenvolvidas e as condições de trabalho docente; analisar propostas de Educação do Campo desenvolvidas pelo município em estudo, bem como os materiais que regulam o trabalho docente; investigar os contextos não escolares, como associações, cooperativas, organizações e movimentos sociais presentes; e pesquisar sobre o fechamento de escolas do campo, suas causas e implicações.

No decorrer deste trabalho, por questões de sigilo e ética da pesquisa, optou-se pela utilização de nomes fictícios para os colaboradores da pesquisa, visando preservar suas identidades. Vale lembrar que os nomes fictícios foram escolhidos pelos participantes, sendo assim, o nome da professora será Margarida e o da coordenadora será Eliane.

Os princípios teóricos que orientam este estudo pautam-se nas discussões e reflexões tecidas sobre Educação do Campo no Brasil, tansversalizando questões importantes no âmbito de sua trajetória política, social e educacional. Para tanto, utilizamos os trabalhos de Caldart (2002; 2004), Fernandes (2012), Pires (2012), Ribeiro (2012), dentre outros autores que problematizam questões importantes no âmbito da Educação do Campo, entendida como uma realidade contemporânea que se constitui como um direito dos povos do campo, uma dívida histórica e social brasileira.

Em suma, tendo em vista uma melhor sistematização dos elementos a 
serem discorridos, o artigo encontra-se estruturado em cinco seções, sendo que a primeira delas constitui-se por essa introdução. A segunda delas, intitulada "Dimensões Históricas e Políticas da Educação do Campo: Transitando entre as (Im)possibilidades", tece discussões sobre o contexto histórico e social de consolidação da Educação do Campo no Brasil, evidenciando as dificuldades e os desafios existentes nesse processo. A terceira, "Percursos Metodológicos:

Desvelando Caminhos", apresenta as abordagens metodológicas utilizadas e os instrumentos empregados para a realização do trabalho. A quarta, "Experiências de Educação do Campo: Relatos das Colaboradoras", traz os resultados e discussões da pesquisa realizada, com vistas a apresentar dados importantes desse estudo. E por fim, a quinta, "Considerações Finais: (In)conclusões", seção que expõe as principais evidências resultantes do trabalho de pesquisa.

\section{Dimensões históricas e políticas da Educação do Campo: transitando entre as (Im)possibilidades}

A Educação do Campo refere-se a um contexto educacional que tem suas origens marcadas pela representatividade das lutas dos movimentos sociais camponeses, que buscam o direito por uma educação pensada especificamente para a realidade do Campo, levando em consideração as culturas e os costumes da sua população. Dessa forma, dentre os diversos movimentos sociais camponeses existentes, destaca-se o protagonismo desempenhado pelo Movimento dos Trabalhadores Rurais Sem Terra (MST), que foi fundamental para a conquista de diversos avanços ao longo dos anos.

Nessa conjuntura, é pertinente lembrar que ainda na atualidade tais movimentos são fundamentais para o alcance dos objetivos educacionais e sociais existentes. A Educação do Campo constitui-se como um paradigma em construção, caracterizada por englobar todos os espaços campesinos. Assim sendo, o contexto educacional precisa levar em consideração as especificidades dessa população, preocupando-se com suas singularidades e particularidades históricas, sociais, culturais, políticas e econômicas que são transversalizadas, no contexto brasileiro, por dimensões ligadas à questão agrária e à luta pela terra.

Nessa perspectiva, conforme as Diretrizes Operacionais para a Educação Básica nas Escolas do Campo ${ }^{\mathrm{ii}}$ vêm destacando,

A educação do campo ... tem um significado que incorpora os espaços da floresta, da pecuária, das minas e da agricultura, mas os ultrapassa ao 
acolher em si os espaços pesqueiros, caiçaras, ribeirinhos e extrativistas. $\mathrm{O}$ campo, nesse sentido, mais do que um perímetro não urbano, é um campo de possibilidades que dinamizam a ligação dos seres humanos com a própria produção das condições da existência social e com as realizações da sociedade humana (Brasil, 2002, p. 1).

Nesse sentido, as diretrizes defendem uma educação que leve em consideração todos os sujeitos em seus modos de vida e de existência humana, ultrapassando os limites físicos do espaço, mas apropriando também todo um contexto de heterogeneidades existentes. Dessa forma, apontam o campo como um meio fundamental de possibilidades e de relações das pessoas com a sua própria produção histórica e cultural. Nessa perspectiva, um dos maiores objetivos da Educação do Campo é a busca pela emancipação humana, proporcionando aos sujeitos se tornarem protagonistas da sua própria história.

Nesse viés, é importante destacar a diferença conceitual existente entre a Educação do Campo e a Educação Rural. Durante muito tempo a nomenclatura utilizada para se referir aos processos educacionais nos espaços camponeses era a Educação Rural, termo esse que foi registrado pela primeira vez durante o Primeiro Congresso de Agricultura do Nordeste Brasileiro ${ }^{\text {iii }}$.
Essa época foi marcada pela existência de um grande movimento migratório das pessoas que moravam no campo e que iam viver na cidade em busca de melhores condições de vida. Assim, o objetivo do mencionado evento era evitar a migração e manter a população no campo, de modo que a Educação Rural “privilegiava o estado de dominação das elites agrárias sobre os(as) trabalhadores(as), principalmente para estabelecer a harmonia e a ordem nas cidades e elevar a produtividade do campo" (Pires, 2012, p. 81).

Nesse período, surge o Ruralismo Pedagógico, um movimento educacional caracterizado pelo ideal de fixação da população rural no campo, buscando evitar a migração de um grande número de pessoas para os centros urbanos. É nessa perspectiva que Pires (2012, p. 82) ressalta que:

O ruralismo pedagógico foi reforçado pela ideologia do colonialismo, a qual se pautava na defesa das virtudes do campo e da vida campesina para esconder a preocupação com o seu esvaziamento populacional, o enfraquecimento social e político de patriarcalismo e a forte oposição, por parte dos agroexportadores, ao movimento progressista urbano. Ao lado disso, o ruralismo teve outros apoios como o de alguns segmentos das elites urbanas, que apregoavam a fixação do homem/mulher no campo como forma de evitar a explosão de 
problemas sociais nas cidades (Pires, 2012, p. 82).

Frente a isso, podemos perceber que a existência do Ruralismo Pedagógico é marcada por uma série de ideologias da elite dominante e obteve grande repercussão na sociedade, visto que trouxe consequências para a forma com que os processos educativos aconteciam. Isso enfatiza mais uma vez que a educação direcionada para as áreas rurais vai se constituindo a partir dos interesses do Estado brasileiro e essa realidade é evidente nos mais diferentes aspectos associados à educação voltada ao campo.

Neste ponto, reiteramos que as diferenças conceituais entre a Educação Rural e a Educação do Campo tornam-se visíveis, pois enquanto a Educação Rural refere-se a "uma educação na mesma modalidade da que é oferecida às populações que residem e trabalham nas áreas urbanas, não havendo ... nenhuma tentativa de adequar a escola rural às características dos camponeses" (Ribeiro, 2012, p. 295), a Educação do Campo se refere a uma educação pensada especificamente para os sujeitos do campo, levando em consideração as suas pluralidades.

Ainda nessa vertente, ao analisar as origens da expressão Educação do Campo, percebe-se que ela é marcada pela I Conferência Nacional por uma Educação
Básica do Campo, um evento que foi realizado em 1998 na cidade de Luziânia (Goiás) e que reuniu professores e movimentos sociais para discutir sobre a educação que era ofertada nas áreas rurais. A partir desse evento, é consolidada a expressão "Educação Básica do Campo" e, segundo Caldart (2004, p. 1), “o momento do batismo coletivo de um novo jeito de lutar e de pensar a educação para o povo brasileiro que trabalha e vive no e do campo", pois busca-se uma educação que respeite as especificidades do campo, sem inferiorizá-las. Isso, inclusive, fica em evidência nos próprios objetivos do evento, quando se afirma que é de:

Ajudar a recolocar o rural, e a educação que a ele se vincula, na agenda política do Brasil. Todos que participamos na promoção desse evento, partilhamos da convicção de que é possível, e necessário, pensar/implementar um projeto de desenvolvimento para o Brasil que inclua a milhões de pessoas que atualmente vivem no campo, e de que a educação, além de um direito, faz parte dessa estratégia de inclusão (Brasil, 1998, p. 5).

Além disso, em 2002 aconteceu outro evento muito marcante em Brasília: o Seminário Nacional por uma Educação do Campo. É nesse evento que a expressão "Educação do Campo" ganha força e consolida-se, impulsionando as reflexões e discussões sociais e educacionais acerca da temática. 
Mediante a isso, é importante frisar a fundamental importância que os movimentos sociais desempenham para cada um dos marcos e dos avanços referentes à Educação do Campo. Assim, movimentos como os Centros Populares de Cultura (CPC), os Sindicatos, as Organizações não-governamentais (ONGs), a Via Campesina, o Movimento de Mulheres Camponesas (MMC), o Movimento dos Atingidos pelas Barragens (MAB), além de outros, são fundamentais para as conquistas alcançadas. Nesse contexto, destaca-se o Movimento dos Trabalhadores Rurais Sem Terra (MST), articulando a luta pela terra com a luta pela educação.

O MST é um movimento socioterritorial que reúne em suas bases diferentes categorias de camponeses pobres - como parceiros, meeiros, posseiros, minifundiários e trabalhadores assalariados chamados sem-terra - e também diversos lutadores sociais para desenvolver as lutas pela terra, pela Reforma agrária e por mudanças na agricultura brasileira. (Fernandes, 2012, p. 498).

Vale ressaltar ainda que, inclusive na contemporaneidade, tais movimentos continuam possuindo imensa importância, pois ainda existem muitos desafios a serem enfrentados, sendo possível perceber a existência de uma série de descasos que envolvem a Educação do Campo, principalmente no que se refere à estrutura das escolas, materiais didáticos disponíveis, condições de trabalho dos professores, dentre outros fatores. Nesse sentido, um dos aspectos que mais tem chamado à atenção na atualidade é o fechamento das escolas do Campo, fato que traz implicações e consequências para toda a população camponesa.

\section{Percursos metodológicos: desvelando caminhos}

No que se refere aos princípios metodológicos, esta investigação se insere no campo das pesquisas qualitativas, por considerar dimensões subjetivas e realidades que não podem ser quantificadas no decurso da investigação, bem como no tratamento dos dados. Nesse sentido, corroboramos com Minayo (2001) quando afirma que a pesquisa qualitativa trabalha com o universo de significados, motivos, aspirações, crenças, valores e atitudes, o que corresponde a um espaço mais profundo das relações, dos processos e dos fenômenos que não podem ser reduzidos à operacionalização de variáveis mensuráveis.

Segundo Chizzotti (2003, p. 221), o termo qualitativo "implica uma partilha densa com pessoas, fatos e locais que constituem objetos de pesquisa, para extrair desse convívio os significados visíveis e latentes que somente são 
perceptíveis a uma atenção sensível". Isso demonstra a amplitude conferida pelo contexto pesquisado e a importância de que todos esses elementos sejam evidenciados.

Nessa perspectiva, realizamos uma pesquisa de campo que possibilitou uma maior aproximação com os fenômenos estudados. Sob esse prisma, convém destacar que a pesquisa de campo permite pesquisar na prática os elementos envolvidos no estudo, num contexto em que há um encontro entre o pesquisador e o campo empírico da sua investigação.

Desse modo, as informações colhidas por meio de uma ida a campo são extremamente valiosas para a construção do conhecimento, pois revelam fatos $\mathrm{e}$ detalhes que enriquecem grandemente o desenvolvimento do trabalho. Com base nisso, de acordo com as palavras de Gonçalves (2001, p. 67),

É o tipo de pesquisa que pretende buscar a informação diretamente com a população pesquisada. A pesquisa de campo é aquela que exige do pesquisador um encontro mais direto. Nesse caso, o pesquisador precisa ir ao espaço onde o fenômeno ocorre, ou ocorreu e reunir um conjunto de informações a serem documentadas (Gonçalves, 2001, p. 67).

Por meio disso, é possível perceber que a realização da pesquisa de campo constituiu-se um indispensável elemento da pesquisa, sendo fundamental para a busca dos objetivos propostos. Portanto, cada uma das informações colhidas empiricamente foi fundamental para o processo da pesquisa e para os seus resultados.

A pesquisa em questão foi realizada durante o mês de Junho de 2016 na Secretaria de Educação de Elísio MedradoBA e em uma escola da rede municipal situada no povoado Serrote, zona rural desse mesmo município. Sendo assim, nesta investigação buscamos compreender o movimento da Educação do Campo no Vale do Jiquiriçá-BA e, mais especificamente, no munícipio de Elísio Medrado, através da construção de inventários da realidade e de retratos singulares dos contextos investigados.

Para tanto, utilizamos como instrumento de coleta de dados a entrevista semiestruturada, que foi realizada tanto com a coordenadora das escolas do campo da região quanto com uma professora que leciona em uma das turmas multisseriadas dos Anos Iniciais do Ensino Fundamental. A escolha por este instrumento de pesquisa se deu pela possibilidade de aproximação com os sujeitos e devido à sua flexibilidade no decorrer do trabalho, uma vez que organizamos um roteiro de perguntas que permitiu a inserção de outras questões ao longo do diálogo.

Compreende-se a entrevista semiestruturada como uma entrevista na qual 
as perguntas principais são pré-definidas e organizadas através de um guia/roteiro, de modo que tais perguntas estão diretamente relacionadas aos objetivos traçados na investigação. Contudo, além dessas questões iniciais, novas indagações podem surgir no decorrer da conversa, o que permite uma abordagem mais consistente e contextualizada acerca da temática.

Para Manzini (1990/1991, p. 154), "esse tipo de entrevista pode fazer emergir informações de forma mais livre $\mathrm{e}$ as respostas não estão condicionadas a uma padronização de alternativas". Neste estudo, as entrevistas foram agendas previamente com as colaboradoras, gravadas em áudio, transcritas, posteriormente categorizadas e analisadas.

No que se refere à importância da entrevista, Marconi e Lakatos (2007, p. 197) apontam que:

A entrevista é um encontro entre duas pessoas, a fim de que uma delas obtenha informações a respeito de determinado assunto, mediante uma conversação de natureza profissional. É um procedimento utilizado na investigação social, para a coleta de dados e para ajudar no diagnóstico ou no tratamento de um problema social (Marconi \& Lakatos, 2007, p. 197).

Diante do exposto, podemos perceber a complexidade envolvida na realização das entrevistas e a fundamental relevância que elas possuem. A partir da sua realização é possível colher dados e informações que contribuem para a compreensão de uma série de elementos do contexto investigado, de modo que a utilização desse instrumento se mostrou imprescindível neste trabalho.

Tendo em vista esses elementos, o uso da entrevista possibilitou evidenciar e aprofundar representações sobre as experiências e as realidades educativas dos sujeitos, bem como entender os diferentes mecanismos e os processos históricos relativos à educação em seus diferentes tempos e espaços na região investigada. Devido a isso, o trabalho com as entrevistas contribuiu na compreensão acerca da história local, principalmente no que se refere ao cotidiano vivenciado pelas participantes da pesquisa.

Nesse viés, as perguntas da entrevista realizada com a coordenadora tratavam basicamente de questões acerca de aspectos que evidenciam a forma com que a Educação do Campo é conduzida no município. Neste ponto, durante o diálogo, buscamos conhecer a proposta de Educação do Campo do município e há quanto tempo ela foi implementada; investigar se o município oferece alguma formação específica ou continuada para os professores do campo; identificar se existe alguma parceria entre a secretaria e alguma organização social; e colher dados sobre a quantidade de escolas do campo existentes 
no município, incluindo quantas delas foram fechadas e quais os motivos do fechamento.

Já as questões da entrevista realizada com a professora abordavam aspectos relacionados ao seu cotidiano escolar, às características das suas práticas pedagógicas, a sua relação com os alunos e com a comunidade e a sua concepção de Educação do Campo. Além disso, buscouse trazer reflexões sobre o fechamento das escolas do campo e sobre as suas condições de trabalho, no que se refere a salário, carga horária, materiais didáticos, dentre outros aspectos.

O município de Elísio Medrado se localiza no Recôncavo da Bahia, a cerca de 240 quilômetros da capital Salvador, com uma área total de aproximadamente 100 $\mathrm{km}^{2}$; onde se encontra uma população estimada em 7.947 habitantes e uma densidade demográfica de 41,6 hab./ km², (IBGE, 2010). Sua população é predominantemente rural, isso explica o fato da sua economia ser baseada principalmente na agricultura familiar. A economia do município gira em torno da agricultura, principalmente através do cultivo da mandioca, laranja, feijão e outros produtos agrícolas.

A comunidade do Serrote já possuiu uma cooperativa, mas no momento de realização do estudo encontrava-se desativada. Convém frisar que a comunidade do Serrote já teve várias escolas, no entanto, atualmente a única que está em funcionamento é a escola onde essa pesquisa foi realizada.

A instituição escolar onde realizamos a pesquisa apresenta uma estrutura física razoável, possui duas salas de aula, uma cozinha, uma secretaria e dois banheiros. Não possui área de recreação, o único local disponível para as crianças brincarem é uma área no exterior da escola, próxima à estrada e sem proteção nenhuma. Pelo que foi possível perceber, as crianças utilizam o espaço da própria sala de aula para brincarem. É importante lembrar que nessa instituição as classes são multisseriadas, sendo que há duas turmas, uma para atender as crianças do G4, G5 e $1^{\circ}$ ano, e a outra turma o $3^{\circ}$, o $4^{\circ}$ e $5^{\circ}$ anos.

\section{Experiências de Educação do Campo: relatos das colaboradoras}

A partir da entrevista realizada com a coordenadora das escolas do campo do município pesquisado, foi possível constatar que apesar de as escolas no perímetro rural serem registradas como Educação do Campo, o que ocorre é um ensino urbanocêntrico, no qual se utiliza o mesmo currículo das escolas urbanas para educar os alunos que vivem no campo, não considerando assim, as especificidades 
dessas localidades e dos sujeitos que ali vivem e estudam. Neste ponto, quando questionada em relação ao currículo escolar e se existe uma proposta especifica de Educação do Campo no município, a coordenadora respondeu que:

Não, a proposta pedagógica do município é só uma, voltada para todas as escolas do município, não tem uma proposta especifica só procampo não. (Eliane, entrevista, 2016).

Com base nessa assertiva, podemos constatar que isso é algo muito sério, pois foge totalmente dos princípios da Educação do Campo, que prioriza que os indivíduos tenham acesso à educação no seu local de origem e que considere suas culturas, ou seja, uma educação que seja no e do campo. Nesse sentido, Caldart (2002, p. 149) defende uma educação que seja:

No: o povo tem direito a ser educado no lugar onde vive; Do: o povo tem direito a uma educação pensada desde o seu lugar e com a sua participação, vinculada a sua cultura $\mathrm{e}$ as suas necessidades humanas $\mathrm{e}$ sociais.

Além disso, outro ponto importante a ser destacado é o fato de que as classes multisseriadas também constituem-se como um elemento marcante da Educação do Campo e, ao analisar especificamente a realidade educacional do município de Elísio Medrado, foi possível identificar que todas as escolas que estão em funcionamento atualmente são classes multisseriadas. A multisseriação se caracteriza por tratar-se de um ensino em que o mesmo professor leciona em uma turma composta por alunos de diferentes idades e diferentes séries. Nessa conjuntura, durante a entrevista com a professora, ela nos afirma que:

Então... eu acho muito importante essa escola estar em funcionamento aqui na comunidade. Muitas pessoas falam assim "Ah a classe é multisseriada, dá muito trabalho, trabalhoso de mais trabalhar com várias séries juntas". Realmente, é muito trabalhoso sim, mas a gente sabe que não tem como formar uma turma no campo só com uma série só, por que a gente tem o que? Vamos supor três de segundo, três de terceiro, um G5... Então como é que vai formar uma turma específica pra cada série? Então é por isso que acontece as multisseriadas. (Margarida, entrevista, 2016).

Dessa forma, podemos perceber que a professora apresenta uma série de argumentos pelos quais a existência da multisseriação se configura como um elemento de extrema importância para a Educação do Campo. Realmente, muitas vezes, as classes multisseriadas são vistas como inferiores e negativas, devido ao fato de geralmente serem escolas com poucos recursos e estruturas precárias. Nesse mesmo sentido, "essas situações expressam a precariedade das condições existenciais em que se encontram as escolas multisseriadas e o conjunto de professores 
e estudantes que vivenciam a educação nesse espaço socioterritorial”. (Barros et al., 2010, p. 27).

Sob esse prisma, vale destacar a importância de políticas públicas voltadas para superar a existência dessa inferiorização para com as turmas multisseriadas, pois é evidente que tais classes são importantes para a formação dos alunos e, em muitos casos, são sua única opção para se ter acesso ao estudo. Nessa perspectiva, é muito importante que haja investimentos em diversos fatores, visando à valorização das classes multisseriadas. Dentre esses fatores, está a melhoria da infraestrutura das escolas, o investimento em materiais didáticos $\mathrm{e}$, sobretudo, uma formação adequada de professores que considere essa realidade.

Dessa forma, a professora Margarida ressalta em outro trecho da entrevista que é importante que:

Prepare bem os professores que for trabalhar na escola do campo, pra que realmente o aluno tenha um ensino de qualidade, que o foco maior ali é o aluno. (Margarida, entrevista, 2016).

Esses relatos nos revelaram condições singulares de seu trabalho em classes multisseriadas, demarcando concepções, posicionamentos e práticas que atravessam um discurso de valorização da escola do campo, bem como de seus sujeitos. Portanto, corroborando com essas afirmativas:

As escolas multisseriadas, para atingirem o padrão de qualidade definido em nível nacional, necessitam de professores com formação pedagógica, inicial e continuada, instalações físicas e equipamentos adequados, materiais didáticos apropriados e supervisão pedagógica permanente (Brasil, 2008, p. 3).

Além disso, durante as entrevistas, um elemento muito importante discutido refere-se ao fechamento das escolas do campo. No município pesquisado, segundo a coordenadora Eliane, nos últimos três anos já foram fechadas no mínimo quatro escolas e ela ainda acredita que novas escolas serão fechadas em breve. Um dos fatores relacionados a isso é a nucleação escolar, que consiste em um processo de transferência dos alunos das escolas desativadas para centros maiores. Assim, segundo Eliane, o fechamento das escolas é provocado pela falta de alunos, como podemos observar nas palavras da mesma, quando questionada sobre o assunto:

É, foram fechadas, me parece...em dúvida... três ou quatro, foram fechadas por falta de aluno, porque são determinadas localidades que não vai surgindo crianças e aí vai ficando cinco, quatro, três alunos, aí não tem como funcionar escola em uma localidade com essa quantidade de aluno porque gera despesas, né? Aí vai fechando por falta mesmo de alunos. Agora mesmo aconteceu de reabrir uma que antes não tinha 
aluno, mais aí fizeram, o pessoal da comunidade fizeram movimento e tal e aí foi surgindo casos de novas crianças e aí já teve como reabrir. Mas foi fechada umas 4 escolas nos últimos 3 anos. (Eliane, entrevista, 2016).

Nesse sentido, podemos perceber nas falas da Coordenadora das escolas do campo, implicitamente, como os interesses econômicos estão presentes e influenciam diretamente a educação. $\mathrm{O}$ processo de nucleação das escolas é uma alternativa das prefeituras para reduzir gastos com funcionários, com professores e com a manutenção das escolas em funcionamento. Assim, ao invés de pagar vários funcionários e gastar com a manutenção de escolas, a opção mais viável para esse modelo educacional enfrentado pelo Brasil é a transposição dos alunos e a efetivação constante da nucleação.

Nesse mesmo contexto, ao questioná-la sobre o que acontece com os alunos quando a escola é fechada, ela afirma que eles "são remanejados para a zona urbana, aí tem transporte". Isso nos evidencia o quanto o fechamento dessas escolas traz consequências para os alunos, já que eles têm que sair da comunidade em que vivem, sendo que muitas vezes os transportes são inadequados e estão em péssimas condições, de modo que põem suas vidas em risco. Ainda sobre o fechamento dessas escolas, a Margarida destaca que:

Eu não concordo com o fechamento das escolas do campo, por conta do... eu falo assim, a criança mora aqui, aí passa em frente à escola que fica pertinho da sua casa e tem que estudar na sede, só pra desmanchar o multisseriado né, geralmente é por causa disso que as escolas do campo estão fechando. Eu não concordo não. (Margarida, entrevista, 2016).

Em síntese, um ponto crucial a destacar diz respeito à concepção de Educação do Campo que a professora e a coordenadora entrevistadas possuem e quais os significados que elas atribuem às escolas do campo. Sendo assim, a coordenadora nos expõe que:
Ah, as escolas do campo é assim, uma coisa maravilhosa ... Então eu acho que é assim muito louvável a localidade que tem uma escola ali perto para os alunos ficarem na sua comunidade, todo mundo ali entrosados, envolvidos, isso é bem melhor do que tá se locomovendo pra zona urbana, né? (Eliane, entrevista, 2016).

Nesse mesmo sentido, percebe-se a grande importância atribuída à Educação do Campo pela professora. Assim, ao falar sobre isso, ela retoma a existência de um processo histórico na comunidade, onde os alunos que lá residiam, tinham que sair para estudar longe. Tais fatos, realmente, demonstram a importância que as escolas do campo possuem. Portanto, nas suas palavras: 
Muita importância! É tanto que teve uma época que as crianças tinham que sair daqui e ir pra uma escola mais adiante. Teve pais que nem quis né, por conta de que o filho estudasse próximo à casa deles né, próximo de casa, bem melhor, no caso deles que são crianças que têm quatro, cinco anos, ter que se deslocar daqui, pegar transporte e ir pra outra escola longe da sua casa né. Então, eu acho muito importante essa escola estar em funcionamento aqui na comunidade. (Margarida, entrevista, 2016).

Em face disso, observa-se a fundamental relevância atribuída pela professora às escolas do campo, bem como os sentidos que essas escolas representam para os sujeitos, para que os mesmos tenham acesso à educação em seu próprio local de origem. Dessa forma, após as entrevistas com a professora e com a coordenadora, é possível conhecer diversos aspectos da realidade educacional vivenciada pelos povos do campo no município de Elísio Medrado, estabelecendo relações com todo um processo histórico e social de inferiorização dos sujeitos residentes no campo brasileiro.

\section{Considerações finais: (In)conclusões}

Historicamente, a Educação do Campo vem enfrentando uma série de desafios e dificuldades. Nesse processo, sabe-se a relevância que os movimentos sociais desempenham, entretanto, sabemos que ainda há muito a avançar e que os desafios não param. Dessa forma, o trabalho de investigar a realidade educacional do campo caracteriza-se como um momento relevante para a (re)construção de atividades, reunindo aprendizagens e experiências.

Desse modo, ressaltamos que a pesquisa, "Retratos da Educação do Campo: Cenários Contemporâneos", revelou que a Educação do Campo na cidade de Elísio Medrado e, mais especificamente, no povoado do Serrote, integra uma realidade brasileira e baiana, que transita entre o descaso e a valorização da educação para os povos do campo. Dessa forma, se por um lado o estudo revelou a importância da Educação do Campo para as participantes da pesquisa, por outro, observa-se que na prática predomina a existência de uma educação urbanocêntrica, que apresenta um currículo homogêneo, descolado dos contextos dos estudantes.

O estudo evidenciou ainda que, embora o município em estudo possua um projeto educacional registrado na secretaria de educação com a nomenclatura "Educação do Campo", identifica-se que não há uma organização curricular específica para o campo, mas sim, a adaptação de um modelo, distanciando-se dos princípios e das concepções que 
pautam o movimento por uma Educação do Campo no Brasil.

Esta pesquisa revelou também uma expressividade no fechamento das escolas do campo no município de Elísio Medrado-BA, fenômeno que ocorre também no cenário nacional. $\mathrm{O}$ fechamento dessas escolas tem acarretado implicações diversas nas comunidades e nas vidas dos sujeitos do campo, questões que serão investigadas com profundidade em pesquisas futuras. Os critérios e justificativas para o fechamento advêm de um discurso econômico do poder público desprovido de uma análise mais apurada no que tange as dimensões sociais e educacionais.

Concluindo, ressaltamos a importância desse estudo para o diagnóstico de contextos específicos, o que nos convoca para a ampliação e aprofundamento de questões evidenciadas no mesmo, no que se refere à Educação do campo. Ainda que o contexto investigado apresente movimentos de avanço na materialização da Educação do Campo, identificamos na contemporaneidade a predominância de retratos de uma educação rural, por isso, 'nosso tempo é de urgências', sigamos!
Barros, O. F., Hage, S. M, Corrêa, S. R. M, \& Moraes, E. (2010). Retratos de Realidade das Escolas do Campo: multissérie, precarização, diversidades e perspectivas. In Antunes-Rocha, M. I., \& Hage, S. M. (Orgs.). Escola de Direito: Reinventando a Escola Multisseriada (pp. 25-34). Belo Horizonte, MG: Autêntica.

Brasil. (1998). Centro de Treinamento Educacional da CNTI. Conferência Nacional por uma Educação Básica do Campo. 27 a 31 de Julho de 1998. Luziânia, GO. Recuperado de: http://unesdoc.unesco.org/images/0014/00 1497/149798porb.pdf

Brasil. (2008). Ministério da Educação. Resolução $N^{\circ}$ 2, de 28 de Abril de 2008. Brasília, DF: MEC.

Brasil. (2002). Ministério da Educação. Diretrizes Operacionais para a Educação Básica nas Escolas do Campo. Resolução CNE/CEB 1, de 3 de Abril de 2002.

Caldart, R. S. (2004). Pedagogia do Movimento Sem Terra. São Paulo: Expressão Popular.

Caldart, R. S. (2002). Por uma Educação do Campo: traços de uma identidade em construção. In Arroyo, M. G., Caldart. R. S., \& Molina, M. C. (Orgs). Por Uma Educação do Campo (pp. 148-158). Petrópolis, RJ: Vozes.

Chizzotti, A. (2003). A Pesquisa Qualitativa em Ciências Humanas e Sociais: Evolução e Desafios. Revista Portuguesa de Educação, 16(2), 220-236 Recuperado de: http://www.grupodec.net.br/wpcontent/uploads/2015/10/Pesquisa_Qualitat iva_em_Ciencias_Sociais_e_Humanas_Evolucoes_e_Desafios_1_.pdf

Fernandes, B. (2012). A Reforma Agrária que o Governo Lula fez e a que pode ser feita. In Sader, E. (Org.). 10 anos de 
governos pós-neoliberais no Brasil: Lula e Dilma (pp. 494-518). São Paulo: Boitempo Editorial.

Gonçalves, E. P. (2001). Iniciação à pesquisa científica. Campinas. SP: Editora Alínea.

IBGE. Censo Demográfico 2010 Recuperado de: https://cidades.ibge.gov.br/brasil/ba/elisiomedrado/panorama

Manzini, E. J. (1990/1991). A entrevista na pesquisa social. Didática, 26/27, 149-158.

Marconi, M. A., \& Lakatos, E. M. (2007). Fundamentos de Metodologia Científica. São Paulo: Atlas.

Minayo, M. C. S. (Org.). (2001). Pesquisa Social. Teoria, método e criatividade. Petrópolis: Vozes.

Pinheiro, M. S. D. (2011). A Concepção de Educação do Campo no Cenário das Políticas Públicas da Sociedade Brasileira. Recuperado de: http://www.anpae.org.br/congressos_antig os/simposio2007/289.pdf

Pires, A. (2012). M. Educação do Campo como Direito Humano. São Paulo: Cortez. Coleção Educação em Direitos Humanos.

Ribeiro, M. (2012). Educação Rural. In Caldart, R. S., Pereira, I. B., Aletejano, P., \& Frigotto, G. (Orgs.). Dicionário da Educação do Campo (pp. 295-301). Rio de Janeiro, São Paulo: Escola Politécnica de Saúde Joaquim Venâncio. Expressão Popular.

i O Território de Identidade Vale do Jiquiriçá localiza-se no centro sul da Bahia, composto por 20 municípios: Amargosa, Brejões, Cravolândia, Elísio Medrado, Irajuba, Itaquara, Itiruçu, Jaguaquara, Jiquiriçá, Lafaiete Coutinho, Laje, Lajedo do Tabocal, Maracás, Milagres, Mutuípe, Nova
Itarana, Planaltino, Santa Inês, São Miguel das Matas e Ubaíra.

ii As Diretrizes Operacionais para a Educação Básica nas Escolas do Campo, promulgada em 2001 e instituída através da resolução $n^{\circ} 1$, de 3 de abril de 2002, trata-se de um documento oficial que estabelece diretrizes, normas e princípios para o atendimento educacional das escolas básicas do campo. É relevante ressaltar que a aprovação dessas diretrizes representa um avanço muito importante para a educação, tendo em vista sua contribuição na perspectiva legal e prática para a efetivação da Educação do Campo.

iii O Primeiro Congresso de Agricultura do Nordeste Brasileiro foi um evento realizado em Recife - PE, em 1923, que reuniu várias pessoas para tratar acerca das questões agrárias camponesas e do trabalho no campo. A proposta do evento era criar meios para reverter a migração existente do campo para a cidade, visando estimular a inclusão da população nas atividades de agricultura.

Recebido em: 28/02/2017

Aprovado em: 17/03/2017

Publicado em: 30/03/2018

Como citar este artigo / How to cite this article / Como citar este artículo:

APA:

Santos, M. A., Santos, A. A., Orrico, M. C. S., \& Meireles, M. M. (2018). Retratos contemporâneos da Educação do Campo: movimentos investigativos no Vale do Jiquiriçá-BA. Rev. Bras. Educ. Camp., 3(1), 204-222.

ABNT:

SANTOS, M. A.; SANTOS, A. A.; ORRICO, M. C. S.; MEIRELES, M. M. Retratos contemporâneos da Educação do Campo: movimentos investigativos no Vale do Jiquiriçá-BA. Rev. Bras. Educ. Camp., Tocantinópolis, v. 3, n. 1, p. 204-222, 2018.

\section{ORCID}

Mônica de Almeida Santos

http://orcid.org/0000-0001-7144-1020 
Santos, M. A., Santos, A. A., Orrico, M. C. S., \& Meireles, M. M. (2018). Retratos contemporâneos da Educação do Campo: movimentos investigativos no Vale do Jiquiriçá-B $A$...

Alcione de Almeida Santos

(iD) http://orcid.org/0000-0002-0356-4309

\section{Maria Célia Santana Orrico}

http://orcid.org/0000-0002-3677-9293

Mariana Martins de Meireles

(iD) http://orcid.org/0000-0003-3288-3023

Todas as quatro autoras foram igualmente responsáveis pela construção de todas as etapas do trabalho, desde a elaboração, análise, interpretação dos dados, escrita e revisão do conteúdo do manuscrito, até a aprovação da versão final a ser publicada. 